\title{
Chinese International Students' Sense of Belonging in North American Postsecondary Institutions: A Critical Literature Review
}

\section{Jia Chen}

University of Windsor

\section{George Zhou}

University of Windsor

\begin{abstract}
Since 2000, an increasing number of Chinese international students have been entering North American universities, and many have experienced issues with a sense of belonging, which in turn can impact their academic and social performance and psychological well-being. However, limited research on this topic focuses exclusively on Chinese international students. Therefore, in order to establish the direction that future research should take, a thorough literature review has been conducted with the aim of exploring those students' perceptions and experiences regarding sense of belonging, establishing the factors that shape this phenomenon, and identifying the impact it has on students and institutions.
\end{abstract}

Keywords: Chinese international students, sense of belonging, integration, student retention

Jis Chen, MEd, has recently graduated from the Faculty of Education, University of Windsor. Her research interest covers international education and teaching English as a second language. Email: chen1cf@uwindsor.ca

George Zhou, PhD. Professor from the Faculty of Education, University of Windsor. He received $\mathrm{PhD}$ from the University of Alberta. He taught at City University of New York before joining the University of Windsor. His research interest covers science and technology education, teacher education, ICT integration with curriculum, parental involvement, and international education. Email: gzhou@uwindsor.ca 


\section{Context}

Since 2000, an increasing number of Chinese international students have been pursuing postsecondary education in North America. In the United States, the number of international students enrolled in higher education programs reached 1,043,839 in the 2015/2016 academic year, which marked a $7.1 \%$ increase from the previous academic year. China remained the top source country in this regard, contributing $31.5 \%$ of the total number of international students in America (Institute of International Education, 2016). In Canada, there were 353,570 international students in 2015, which marked an $8 \%$ increase over the previous year. Among these students, approximately two-thirds were from Asia, with China being the highest sending country (Canadian Bureau for International Education, 2016). This trend was also demonstrated by the Association of Universities and Colleges of Canada (2015), which found that $88 \%$ of Canadian universities consider China as their first choice in terms of their expansion into international markets.

In such a context of ever expanding and diverse higher education population, students' sense of belonging and engagement has become an important topic among administrators and scholars (Masika \& Jones, 2016). Students who have a greater sense of belonging on campus would feel more capable academically, evaluate themselves more positively, and are less likely to externalize problems (Pittman \& Richmond, 2007). Strayhorn (2012) argues that a sense of belonging is of particular importance for individuals who live in a perceived unfamiliar or foreign environment. Students who are not able to have a sense of belonging tend to have negative outcomes. Strayhorn points out that the "deprivation of belongingness needs often leads to diminished interest in life activities, loneliness, self-hatred, disengagement from life (often through suicide) or, in the context of education, disengagement from college through attrition" (p. 23). This suggests a need to examine the extent to which international students-including Chinese-perceive and experience belongingness in foreign educational settings in order for institutions to better facilitate their positive learning experiences. Particularly, limited research is found that focuses exclusively on Chinese international students regarding their sense of belonging in North American campuses. Thus, the objective of this article is to provide a critical review of the literature on the perceptions and experiences toward sense of belonging among Chinese international students, and identify factors that contribute to their adaption and acculturation in North American postsecondary institutions.

\section{Literature Search Methods}

An exhaustive search for papers was carried out to achieve the study objective. Four research strategies were applied: a database search, a search terms strategy, selection criteria, and a manual search.

\section{Database Search}

The electronic inquiries were conducted to locate peer-reviewed journals via our university library. The researchers searched for articles that were identified as relevant to education, social science and psychology. The databases included Education Resources Information Center (ERIC), ProQuest Social Sciences, PsycINFO, and Google Scholar. 


\section{Search Terms}

Several keywords were utilized to ensure the results offered broad coverage. The initial search terms were "Chinese international students" and "belonging". Synonyms for belonging were also included in this process, such as "sense of community", "connectedness", "affiliation", "engagement", "integration", and "fit in". The key terms were then entered into the search engine in conjunction with locational terms such as "Canada", "America", "U.S.", and "North America". These search terms help to determine the scope of the study destinations for those students. Terms related to cultural aspects were then added. These included "culture" and "acculturation". To further narrow the scope, three terms related to subjective evaluations were also used: "experience", "perception", and "attitude". The main search terms were likewise combined with possible outcomes or effects on students, such as "positive experience", "negative experience", "challenges", "well-being", "health", "persistence", and "retention".

\section{Manual Search}

In order to ensure that "grey" literature was included during the search process, reference lists of retrieved studies were reviewed. Searches of websites of organizations related to international education were also incorporated. These included the Institute of International Education, the Canadian Bureau for International Education, and Universities Canada (formerly the Association of Universities and Colleges of Canada).

\section{Selection Criteria}

Further criteria were specified in order to select studies appropriate for the current research. To be included in the review, the literature needed to meet four criteria: it must be written in English; it must be published in the past 17 years (with the exception of a few articles that are deemed to be significant to this study); it must focus on or closely relate to Chinese international students on North American campuses; and it must report on undergraduate or graduate Chinese international students. These inclusion criteria limited the research to 48 studies.

\section{Literature Review}

\section{Need to Belong}

The need to belong has long been regarded as an essential drive for human beings. One commonly known model in this regard is the hierarchy of needs proposed by Maslow (1954), which consists of five levels of needs from the most immediate needs to more subjective needs: physiological needs, safety, love and belonging, self-esteem, and self-actualization. This model indicates that one must satisfy lower-level needs before progressing to meet higher-level needs. It suggests that the physiological needs are humans' fundamental needs, and love and belonging are being positioned in the third level as the psychological needs. However, Maslow's conceptualization of belonging has been considered deficient (Slaten et al., 2014), and there is an emerging body of literature that frames belongingness as a fundamental need.

For example, Baumeister and Leary (1995) propose that humans are driven to establish and maintain significant, long-term, positive, interpersonal relationships. Unlike Maslow's hierarchy of needs, Baumeister and Leary believe that belongingness is almost as fundamental as the need for food. Based on this hypothesis, they describe two main characteristics of the need to belong:

Brock Education Journal, 28(2), 2019 
people need to have persistent interpersonal communications with other people, and they need to feel a stable and affective bond with others that will last through a predictable future. Lambert et al. (2013), however, suggest that the definition of belonging should go beyond a general need like forming a positive social relationship. Instead, belongingness is referred to as subjective experiences based on relationships that offer security through a sense of belonging. Their results indicate that a strong sense of belonging is highly related to a high level of meaningfulness in life. In other words, a sense of belonging is likely to enhance the meaning of lives for individuals.

Alternately, Ryan and Deci (2002) developed the Self-Determination Theory (SDT), which suggests that the need for relatedness is one of the fundamental psychological needs. SDT defines relatedness as a feeling of connection and belonging with others and one's community, which considers how homogenous inclinations shape people's tendency to seek out connections and feel not only accepted by others, but integral to them. This theory suggests that the social environment either fosters or impedes integration. They state that because needs are universal by their very nature, all cultures should share the relationship between satisfying needs and wellbeing. However, because values and goals vary from culture to culture, the way people fulfil their needs can also vary (Ryan \& Deci, 2002).

Strayhorn (2012) focuses on the sense of belonging for postsecondary school students. He regards a sense of belonging as both a cognitive evaluation and a basic need and motivation for human beings, and notes that it leads to affective responses. He deems the sense of belonging to be a dynamic, reciprocal relationship between an individual and a group that must be satisfied on a continual basis. Strayhorn calls this an "I am we and we are each" phenomenon (p. 3), in which the group benefits from the collective effort of its members through their membership, and individuals benefit from the group, which fulfils individuals' needs. He also argues that a sense of belonging is context-based, meaning that it can be especially significant in a perceived unfamiliar or foreign environment and it tends to change over time.

Baumeister and Leary (1995) suggest that those who are socially deprived are more likely to suffer behavioural, psychological, and physical problems, including mental illness, criminal tendencies, and social isolation. Individuals who died by suicide often had higher rates of social isolation, suggesting that a lack of belongingness may lead to suicidal ideation (Van Orden et al., 2008). Similarly, Durkheim (1961) argues that individuals who are not integrated into society are more likely to end their lives through suicide. He outlines two reasons people fail to integrate into society: insufficient moral integration and insufficient collective affiliation. Insufficient moral integration occurs when a person maintains divergent values that do not conform to a society's values, while insufficient collective affiliation occurs when a person does not sufficiently engage in personal interactions (Durkheim, 1961). In order to satisfy the need to belong, people need to realize that others care about their welfare (Baumeister \& Leary, 1995).

It is clear that scholars have been theorizing the sense of belonging as a significant aspect of an individual's well-being. More and more scholars believe that sense of belonging should be considered as a more fundamental need for a psychologically healthy individual.

\section{Sense of Belonging and Student Retention}

Tinto's (1975) model connects a sense of belonging to student persistence. He asserts that for students, a higher level of integration into the college system indicates a higher level of commitment toward their institution and persistence toward completion of their academic program. He points out that integration into the college system is a function of both formal and 
informal interactions for students in both academic and social realms. Inversely, dropping out is the result of a longitudinal process where students do not adequately interact with the institution, which may include peers, faculty, or the administrators. Tinto suggests that although academic integration is the most influential factor in student retention, social integration also has an important role to play in one's degree fulfillment. He defines social integration as "informal peer group associations, semi-formal extracurricular activities, and interaction with faculty and administrative personnel within the college" (p. 107). He argues that when individuals successfully engage in these activities, they can gain personal support through friendships, professional relationships with faculty members, or through collective affiliations while enhancing their social communication. These social rewards can shape how people evaluate the benefits of college and consequently influence institutional commitments.

Building upon Tinto's pivotal work, studies on the relationship between a sense of belonging and student retention have been frequently documented in the literature (Cheng, 2004; Cooper, 2009; Fischer, 2007; Masika \& Jones, 2016; O'Keeffe, 2013). For example, O'Keeffe (2013) found that the student attrition rate in the United States had reached between $30 \%$ and $50 \%$ across higher education, making student persistence a vital issue. This study also found that a sense of belonging was considered as an important predictor of student retention and those universities that endeavour to create a caring and supportive environment for students could facilitate a sense of belonging. Similarly, Cooper (2009) brought the sense of belonging into the context of a diverse campus community. He proposed that students' sense of belonging on campus significantly impacts their educational persistence; therefore, students need to perceive the campus community as a supportive one where they can have both a sense of identity and affinity. The psychological feelings of sense of belonging on campus was also noted by Cheng (2004), who claimed that "students' sense of community is closely associated with their feelings of being cared about, treated in a caring way, valued as an individual and accepted as a part of community and the quality social life on campus" (p. 216). In all, students with more engagement and a sense of belonging in campus life have higher levels of college persistence and better academic performance (Fischer, 2007).

The retention issue is even more problematic among first-year college students. MalingaMusamba (2014) states that first-year students have to cope with transitional dilemmas by finding their position and learning how to negotiate cognitively and socially on campus. Similarly, while new university students face levels of independence and responsibility they have not experienced, Pittman and Richmond (2007) observe that they must also simultaneously struggle with a multiplicity of transitions: domestic arrangements, academic settings, and social networks. Since a sense of belonging is central to student retention, developing a sense of belonging is essential to student success, especially for those who are at risk of non-completion (O’Keeffe, 2013).

\section{Sense of Belonging Among Chinese International Students}

Upon leaving the comforts and social support of their native countries to study abroad, international students lose their sense of social connectedness (Cao, Zhu, \& Meng, 2017; Du \& Wei, 2005). Therefore, international students rely more on host universities compared to local students due to insufficient societal sources (Yan \& Sendall, 2016). They need far more support than domestic students to compensate for decreased security and even social exclusion (Paltridge, Mayson, \& Schapper, 2012). Numerous studies further identified some of the main challenges encountered by international students as academic pressure, language barriers, 
cultural shock, and financial issues (Calder et al., 2016; Slaten, Elison, Lee, Yough, \& Scalise, 2016; Wang, 2016; Yan \& Sendall, 2016; Zhou, Liu, \& Rideout, 2017).

Several studies focused on Chinese international students' acculturation process. For example, Cao et al. (2017) examined Chinese international students' acculturation experiences by analyzing the relationship between sociodemographic factors and social ties, specifically host-national, international, and co-national ties. The results imply that English proficiency and previous adaptation experience are important indicators for Chinese students' social ties. To be more specific, Chinese students primarily choose co-national ties, followed by host-national ties and international ties. The study demonstrates the need for Chinese international students to interact with domestic students and other international students as these social ties can facilitate positive attitudes toward the host culture and better integration into the mainstream society. In addition, Bertram, Poulakis, Elsasser, and Kumar (2014) found that the most prevailing acculturative stressors among Chinese international students were the feeling of isolation from their surroundings, cultural differences, and the language barrier. Moreover, Chinese international students who participated in the study reported lower levels of satisfaction with respect to social support than their American counterparts.

T. Liu (2016) reports similar findings in Canada, where study participants had a limited number of local friends and perceived themselves as disconnected to the Canadian environment. One participant in this study revealed that even attending campus activities did not guarantee her friendship development with natives, nor did volunteer work help to build such relationships. Another study examined how adult attachment and acculturation impact Chinese international students' psychosocial adjustment in America (Wang \& Mallinckrodt, 2006). The study demonstrated that Chinese international students with attachment security were more likely to adjust to a new environment. They argued that, when in unfamiliar environments, adults with secure attachment could access attachment figures and imagine "home" by creating reassuring mental representations, even if loved ones were not present. However, when individuals lacked secure attachments, they struggled to explore social surroundings they were not familiar with as they could not adequately regulate their emotions. Secure attachment allowed Chinese international students to more effectively navigate stressful environments, difficulties, and unfamiliar social settings, and network with people in their social environment, thereby allowing them to develop a social support system and allowing them to better adjust to their new environment. In contrast, Chinese international students with higher levels of attachment avoidance were not likely to seek help when encountering acculturation difficulties as it deterred them from establishing social networks in the host country (Wang \& Mallinckrodt, 2006). Zhou and Zhang (2010) explored Chinese international students' perspectives, expectations, and experiences at a Canadian university, with particular focus on their challenges during the acculturation process. The results showed that English language proficiency, previous education background, peer interaction, and cultural issues all impacted their adjustment in a host campus. For instance, Chinese international students were accustomed to the behaviourist-oriented teaching approach, which is the opposite of the social-constructivist learning approach in the Western educational system, making it a big challenge in learning adaption among Chinese international students. In addition, language barriers and cultural differences discouraged these students from befriending English-speaking peers, sharing residence rooms, and getting involved in group work.

Wang (2016) examined Chinese international students' dropout behaviour from a preuniversity English improvement program in Canada. She applied case studies in order to explore 
their academic and social challenges, explain dropout behaviour, and seek strategies to help Chinese international students better integrate into a new educational system. She discovered that English speaking and writing were the main obstacles to students' academic success. As for oral English, participants frequently mentioned that they did not receive adequate oral English training in Chinese schools. Consequently, their limited ability in oral English hindered their communication with instructors and domestic peers in class, as well as their engagement in group discussions. In terms of English writing, participants reported that the writing style and format in English are significantly different from that of Chinese, which created significant academic challenges for them. With respect to social aspects, participants were more likely to stick to an ethnic group and presented less engagement in the host culture, which hindered them gaining positive social experiences in the host country. Wang found that these participants generally had inadequate social support from friendship networks. Moreover, all participants reported that they were dissatisfied with teacher-student relationships and lacked interactions with their teachers both inside and outside of class. Therefore, the weak teacher-student relationship was a significant factor in students' dropout decisions. In addition, some study participants reported that they experienced discrimination at times and found no place to comfortably search for help.

To ensure that Chinese international students had a voice on campus, Heng (2017) sought to develop an understanding of their overseas college experience to improve transcultural understanding. He found that Chinese international students longed for the cultural background acceptance from their professors and domestic peers and they expected better international student services in interpreting academic norms. The voices of Chinese international students who have been surveyed indicated that they encountered academic uncertainty and suffered emotional stress as they desired patience and encouragement from teachers. Additionally, the demonstration of care and inclusion from domestic peers would enhance these students' motivation, self-esteem, and mental health. Thus, participants hoped that their teachers and host peers would discard stereotypes and make an effort to understand the complex challenges that international students faced.

In terms of mental health issues among Chinese international students, Han, Han, Luo, Jacobs and Jean-Baptiste (2013) surveyed 130 Chinese international students at Yale. They found that $45 \%$ of the students had depression symptoms, $29 \%$ had anxiety symptoms, and $27 \%$ of those students were even unaware of on-campus counseling services. Depression and anxiety were more common among students who failed to develop a positive relationship with the advisors or express themselves regularly, and these students often had negative self-evaluations of their health. Therefore, Han et al. (2013) stressed the importance of student-advisor relationships, and the necessity to improve awareness of mental health and counseling services for Chinese international students.

In summary, while the sense of belonging is a common issue among postsecondary institutions, international students face more challenges than domestic peers in building their connectedness with the host campuses. The relevant literature has demonstrated that Chinese international students experience the lack of integration socially and academically with host institutions, which leads to their poor mental health and attrition from their institutions.

\section{Factors Influencing Sense of Belonging Among Chinese International Students}

Cultural impact. A cultural distance ensues when one's personality does not fit in a new environment (Lee \& Ciftci, 2014), and such a cultural distance between East and West is most 
notable when comparing and contrasting language and cultural customs and practices (Yao, 2016). Zhou and Zhang (2014) note the role of cultural differences:

International students who grew up in another culture usually possess different personal interests, ways of communication, sense of humour, daily routines, and perceptions on many things such as friendship, sexual relationships, and privacy concerns which will negatively influence their willingness and attempts to make close friends with domestic students. (p. 13)

The influence of cultural collectivism has been highlighted in several studies. Lee and Ciftci (2014) state that "in collectivistic cultures, compliance to the group norm is seen as a desirable quality" (p. 99). Likewise, group identification contributes to the improvement of psychological health and well-being; thus, people from collectivist cultures are more likely to receive social support from groups than those from individualist cultures. For example, perceived group support would be more likely to enhance in-group cohesiveness for individuals in collectivist cultures compared with members in individualist cultures (Lambert et al., 2013).

Students from China are generally embedded with the collectivistic culture (Bertram et al., 2014), which means students are taught to be respectful to teachers and accept the knowledge uncritically. It is observed that most of the Chinese students act cautiously and in a reserved manner in American classrooms (Zhang \& Xu, 2007). Similarly, Gebhard (2012) points out that international students, particularly Asian students, face great difficulties during seminars in which students are supposed to ask and answer questions and discuss issues. Zhou et al. (2017) note that due to the lack of a clear concept about the Canadian education system, Chinese international students have no idea how to answer a question in a particular educational context. It can be concluded by what Chiu, Chow, McBride, and Mol (2016) note that students coming from collectivist cultures exhibit more sensitive reactions than students in individualist cultures toward the behaviours and judgments of their classmates. As a result, these students have to temporarily abandon traditional academic norms developed back in China and look for adapting to new academic behaviour (Wang \& Mallinckrodt, 2006).

Power hierarchy also has garnered particular attention in explaining cultural differences. People from egalitarian cultures are assumed to be treated equally despite of their status; however, in terms of hierarchical cultures, people who possess less power have to accept the inequality across different statuses in society (House, Hanges, Javidan, Dorfman, \& Gupta, 2004). Chiu et al. (2016) suggest that students from egalitarian cultures are more likely to have a sense of belonging at school than those from hierarchical cultures. For instance, students in hierarchical countries perceive greater status differences between student and teacher, which results in fewer interactions between the two. This weak teacher-student relationship can reduce students' sense of belonging (Chiu et al., 2016). Moreover, Zhang and Xu (2007) note that North American culture is considered a "small power distance," while Chinese culture is characterized as encompassing "large power distance." Zhang and $\mathrm{Xu}$ note that this is manifested by the fact that a typical American classroom is defined by an atmosphere where teachers and students are equal in interacting with each other. Zhou et al. (2016) conclude that cultural differences come with varying pedagogical approaches, curriculum content, and evaluation standards, all of which can impact the academic outcome of Chinese international students. Similarly, Zhang and Xu (2007) argue that the Chinese students need to make a transition from teacher-oriented and passive-learning approaches to a student-oriented and active-learning approach when they are immersed in a Western learning environment.

Slaten et al. (2016) note that acculturative stress was characterized as having social, academic, 
or emotional challenges associated with students" "international status" and "the host cultural norms" (p. 394), and they impact whether students feel connected to a campus or not. The establishment of a new social bond in a new country is an important criterion of acculturation (Zhou et al., 2017). Unfortunately, the cultural changes may block the establishment of new close friendships when people move abroad; thus, people tend to maintain friendships with old friends (Baumeister \& Leary, 1995). In this respect, Gebhard (2012) points out that one facilitative behaviour used by international students is doing things that remind them of their native culture. This may include hanging out with students of similar cultural background when they feel lost in the host culture.

Langage barrier. Cao et al. (2017) note that language proficiency has always been found to impact an individual's acculturation process and intergroup interaction. They also state that foreign language proficiency is highly associated with Chinese international students' social bonds. The inadequate language proficiency has been marked as the primary acculturative stressor (Slaten et al, 2016; Zhou et al., 2017; Zhou \& Zhang, 2014), and it significantly impacts how an individual effectively deals with academic and social life (Liu, 2016).

For many Chinese international students, the language barrier is the source of embarrassment, a way of disconnection in terms of making friends with local peers (Liu, 2016). Wang (2016) found that English language proficiency impacts Chinese international students when befriending domestic students, resulting in their disconnection with host culture experiences. This failure to establish friendships with local peers, in turn, increases their feelings of loneliness and homesickness. Liu (2016) explored the learning experiences of Chinese international students in a master's program at a Canadian university, and found that the language barrier significantly affected their reading and writing efficiency. A student in Liu's study reported that she was quite confident in English proficiency before coming to Canada, but it turned out to be too difficult for her to figure out a sentence in some assignments, even in instances where she knew every word. With respect to writing, participants reported that they were not familiar with academic writing styles and formats in Canada. Academic requirements in Canada are more demanding than in China, and the difficulties in grammar, punctuation, and vocabulary exacerbate the issue. In addition, Liu notes that English speaking and listening are also considered a challenge for many Chinese international students, as English teaching in China is exam-oriented, and relevant tests are not adequately developed for these skills. She likewise reports that participants who have higher language competence perceived their courses to be less difficult.

Campus characteristics. Tinto (1975) points out that large institutions typically have a more diverse student population and are therefore accustomed to providing support to more diverse student subcultures. Consequently, such schools can more effectively facilitate social integration (Tinto, 1975). Strayhorn (2012) argues that people search for a particular environment where individuals' values, expectations, and attitudes can be consistent with the normative congruence in that environment. Therefore, if a campus has wide and diverse values, students are better able to generate a greater sense of belonging by locating and constructing their particular affiliation on campus. In terms of international students, Hanassab (2006) states that "International students provide the means of diversifying the campus" (p. 169). He points out the relevant programs need to be aware of cultural diversity and have a better understanding of the groups of international students as they represent, which facilitates a campus climate of multicultural and international learning. Slaten et al. (2014) state that a campus without an inclusive environment may be less likely to satisfy students' need to relate, and lead to less campus participation. In 
their study, international students showed appreciation for individuals or groups who acknowledged their similarities as well as differences and were well-advised to create an environment of acceptance to individual uniqueness on campus.

Oseguera and Rhee (2009) further argue that faculty shapes the institutional climate and characters that students are exposed to and engaged with. Similarly, Maestas, Vaquera, and Zehr (2007) observe that when international students have problematic interactions with their instructors, it is likely to inhibit their connectedness with the academic environment, given that staff and faculty are the primary contact point between students and the institution. In order to support and facilitate belonging, Cooper (2009) and Vaccaro, Daly-Cano, and Newman (2015) underscore how important it is for universities to understand their students' needs so that they can provide the comfort and care students required through both internal and external resources. Students' learning experiences can be improved when administrators increase the interactions between students and faculty in order to offer academic guidance and develop some other academic and social activities (Cheng, 2004). It is critical to maintain frequent and regular interactions of international students with academic advisors and faculty members to increase retention among international students (Mamiseishvili, 2012).

Chiu et al. (2016) found that teachers' characteristics were the strongest predictor of students' sense of belonging. Students who developed closer relationships with their teachers received more teacher support and students who came from more well-organized classrooms perceived a greater sense of belonging at school. In searching for Chinese international students' opinion on how U.S. higher education institutions can improve student college experiences, Heng (2017) found that one-third of participants wished their teachers were aware of their backgrounds during teaching and assessment process, and one-quarter of participants wished their teachers considered their language barriers, especially during the first semester. The participants wanted not only to write essays but also desired feedback before submission. Furthermore, a quarter of participants wanted teachers to have more patience with respect to communication. They stated that displays of impatience intimidated them, discouraging them from contributing to class discussions or asking questions. This was consistent with the findings of Liu (2016), who succinctly summarizes this concept: "Changing demographics in education requires more acceptance of diversity, multicultural competence, and social equity and justice among educators" (p. 14).

The presence of international students on campus requires an acceptive environment. However, Guo and Guo (2017) reported that the international students from Asia and the Middle East were not well received and often felt alienated. Some of their study participants had to face biases and discrimination from domestic students, faculty members, and the local community. Similarly, Leask (2009) reported domestic students often avoided working with international students inside class and rarely interacted with them outside class. Heng (2017) reported that the seeming reluctance of Chinese international students to oral communication was often understood as disinterest and their struggles were dismissed as the consequence of their own lack of motivation or interest. This attitude is likely due to the fact that higher education institutions do not investigate the lived experiences of Chinese international students. Consequently, these institutions unintentionally foster a culture of silence among international students as they fail to proactively solicit feedback from the international students to determine what their needs are. The recruitment of international students also requires universities to internationalize their curricula in content, pedagogy, objectives, assessment, and associated support services. However, in practice, "curricula remain Western" (Leask, 2009, p. 272). Guo and Guo also 
reported the international students who participated in their study rarely encountered instructional materials that reflected their experiences.

Information availability. Caidi and Allard (2005) argue that "access to information resources and the skills and literacy needed to make use of information for everyday life problems are part of the social capital of individuals" (p. 307). By extension, this form of social capital is influential with respect to campus belonging for international students. However, the current literature suggests that Chinese international students possess insufficient information associated with their study and life in the host country. Liu (2016) and Yu (2018) found that the lack of knowledge about the local education system contributed to reduced participation among Chinese international students in Canadian education classrooms. Heng (2017) found that students desired greater clarity about administrative information, such as tax and immigration information, to reduce the stress associated with their status as international students. Similarly, Zhang and Zhou (2010) found that Chinese international students expected university to provide them with information and support for their visa application. In their study, participants highly commended their university's soft-landing program, which provides new international students with a pick-up service from the airport, first week shopping assistance, and orientation events and activities in the host academic and social contexts. Yan and Sendall (2016) analyzed how the first-year experience (FYE) program in a Catholic college influenced the experience of international students in higher education. The FYE program provided first-year international students with information on topics such as academic resources, healthy relationships, cultural diversity, social justice, and values. The findings indicate that such a program served to enhance students' awareness of school resource information, deepened their understandings of host and other cultures, facilitated friendship establishment and development, and improved English speaking skills.

\section{Conclusion}

Postsecondary institutions in North America admit international students for various reasons. One of the most commonly described reasons is to diversify their campuses. However, the presence of international students will not automatically lead to a multicultural campus. Research has provided evidence that a sense of belonging is closely related to positive academic, social, psychological, and persistence outcomes for Chinese international students in North American campuses. A limited sense of belonging on campus and the diminished feelings of affiliation toward the community greatly impact the learning and living experiences of those students. This is reflected in several practices: impaired interpersonal relationship with local peers, preferred socialization with home country fellows, limited participation in the host culture, academic uncertainties, communication obstacles, vulnerability to psychological issues such as anxiety and depression, discrimination, limited support, and insufficient information access to important issues such as course selection and tax information. A perceived sense of belonging is beneficial to the well-being of students in terms of their emotional, motivational, and academic functioning. It helps to reduce anxiety, distress, and thoughts of dropping out while enabling students to address challenges with confidence. Postsecondary institutions should develop their programs to better manage and support international students in order to stay competitive in the global education market. Heng (2017) even notes that institutions should eliminate their authoritative and deficit perspectives and give international students agency by making them part of the 
decision-making process. This will encourage institutions to recognize the impact of sociocultural contexts and facilitate equitable exchanges.

Several factors are found to impact sense of belonging for Chinese international students: cultural impact, language barrier, campus characteristics, and information availability. First, Chinese students come from a collectivistic and hierarchical culture. They tend to perform in a reserved and obedient way in class and have less courage to challenge authority, which impacts their learning performance. Second, the language barrier is deemed the most influential factor in the acculturation process. English language proficiency impacts those students in both academic and social realms. Academically, students reported being unfamiliar with academic writing styles and formats in the host country, having difficulties with grammar, punctuation, and vocabulary, and experiencing challenges with English speaking and listening. Socially, English language proficiency impacts Chinese international students when interacting with domestic students and the larger community, leading to disconnection from the host culture. Campus characteristics are also a critical factor. A campus with a large student body or that advocates cultural diversity tends to facilitate students' sense of belonging, as students are eager for identity construction and diversity appreciation on campus. The recruitment of international students will not naturally result in a multicultural campus and not automatically lead to an internationalized curriculum either. It requires efforts from administrators, faculty, and staff to build a welcoming and inclusive social and academic environment for international students. Lastly, information availability is considered a source of social capital. Chinese international students tend to lack access to necessary information, either for academic issues (e.g., course selection, facilities location, academic-related services) or administrative information (e.g., tax and immigration matters). Thus, it is vital to ensure these students have access to such information.

\section{Implications for Future Research}

A critical analysis of the current literature highlights two gaps that future research should seek to address. One issue is that the research scope of this study is North American postsecondary institutions collectively. However, although Canada and the United States share certain cultural similarities, there are significant differences between their education systems. For example, the U.S. relies heavily on private education, while Canada relies primarily on public education. Such a difference might have an impact on the ethnic composition of each system, which in turn could impact the ways in which Chinese international students perceive and acculturate to their academic environment. Therefore, future studies should exclusively focus on one country to elicit more specific perceptions and experiences of Chinese international students within each context. Alternately, comparative studies between the two countries could be done to underscore potential differences. Another issue is that the current research has primarily identified four factors that impact Chinese international students' sense of belonging: cultural impact, language barrier, campus characteristics, and information availability. However, additional factors may be responsible for the construction of sense of belonging, such as socioeconomic background, personal motivation, and learning exceptionalities. These factors might independently impact student outcomes, or be exacerbated by or intensify the impact of the factors that have already been established. Therefore, future research can explore such factors and consider how they impact students and explore their relationship with other factors. 


\section{References}

Association of Universities Colleges of Canada. (2015). Canada's universities in the world: AUCC internationalization survey, 2014. Retrieved from https://www.univcan.ca/wpcontent/uploads/2015/07/internationalization-survey-2014.pdf

Baumeister, R. F., \& Leary, M. R. (1995). The need to belong: Desire for interpersonal attachments as a fundamental human motivation. Psychological Bulletin, 117(3), 497-529. doi:10.1037/0033-2909.117.3.497

Bertram, D. M., Poulakis, M., Elsasser, B. S., \& Kumar, E. (2014). Social support and acculturation in Chinese international students. Journal of Multicultural Counseling \& Development, 42(2), 107-124. doi:10.1002/j.2161-1912.2014.00048.x

Caidi, N., \& Allard, D. (2005). Social inclusion of newcomers to Canada: An information problem? Library \& Information Science Research, 27, 302-324. doi:10.1016/j.lisr.2005.04.003

Calder, M. J., Richter, S., Mao, Y., Burns, K. K., Mogale, R. S., \& Danko, M. (2016). International students attending Canadian universities: Their experiences with housing, finances, and other issues. Canadian Journal of Higher Education, 46(2), 92-110.

Retrieved from http://journals.sfu.ca/cjhe/index.php/cjhe/article/view/184585

Canadian Bureau for International Education. (2016). A world of learning: Canada's performance and potential in international education 2016. Retrieved from https://cbie.ca/wp-content/uploads/2016/05/CBIE-Flagship-2014-E-WEB-RES-final.pdf

Cao, C., Zhu, C., \& Meng, Q. (2017). Predicting Chinese international students' acculturation strategies from socio-demographic variables and social ties. Asian Journal of Social Psychology, 20(2), 85-96. doi:10.1111/ajsp.12171

Cheng, D. X. (2004). Students' sense of campus community: What it means, and what to do about it. NAPSA Journal, 41(2), 216-234. doi:10.2202/1949-6605.1331

Chiu, M. M., Chow, B. W., McBride, C., \& Mol, S. T. (2016). Students' sense of belonging at school in 41 countries. Journal of Cross-Cultural Psychology, 47(2), 175-196. doi: $10.1177 / 0022022115617031$

Cooper, R. (2009). Constructing belonging in a diverse campus community. Journal of College and Character, 10(3), 1-10. doi:10.2202/1940-1639.1085

Du, Y., \& Wei, M. (2015). Acculturation, enculturation, social connectedness, and subjective well-being among Chinese international students. The Counseling Psychologist, 43(2), 299-325. doi:10.1177/0011000014565712

Durkheim, E. (1961). Moral education: A study in the theory and application of the sociology of education (E. K. Wilson \& H. Schnurer, Trans.). New York, NY: Free Press.

Fischer, M. J. (2007). Settling into campus life: Differences by race/ethnicity in college involvement and outcomes. Journal of Higher Education, 78(2), 125-161. doi:10.1353/jhe.2007.0009

Gebhard, J. G. (2012). International students' adjustment problems and behaviors. Journal of International Students, 2(2), 184-193. Retrieved from https://www.academia.edu/7136695/International_Students_Adjustment_Problems_and_B ehaviors

Guo, Y., \& Guo, S. B. (2017). Internationalization of Canadian higher education: Discrepancies between policies and international student experiences. Studies in Higher Education, 42(5), 851-868. doi:10.1080/03075079.2017.1293874 
Han, X., Han, X., Luo, Q., Jacobs, S., \& Jean-Baptiste, M. (2013). Report of a mental health survey among Chinese international students at Yale University. Journal of American College Health, 61(1), 1-8. doi:10.1080/07448481.2012.738267

Hanassab, S. (2006). Diversity, international students, and perceived discrimination: Implications for educators and counselors. Journal of Studies in International Education, 10(2), 157172. doi:10.1177/1028315305283051

Heng, T. (2017). Voices of Chinese international students in USA colleges: "I want to tell them that ...". Studies in Higher Education, 42(5), 833-850. doi:10.1080/03075079.2017.1293873

House, R. J., Hanges, P. J., Javidan, M., Dorfman, P. W., \& Gupta, V. (Eds.). (2004). Culture, leadership, and organizations: The GLOBE study of 62 societies. Thousand Oaks, CA: Sage.

Institute of International Education. (2016). Open Doors 2016: Executive summary: International students in the U.S. Retrieved from http://www.iie.org/Research-andPublications/Open-Doors

Lambert, N., Stillman, T., Hicks, J., Kamble, S., Baumeister, R., \& Fincham, F. (2013). To belong is to matter: Sense of belonging enhances meaning in life. Personality and Social Psychology Bulletin, 39(11), 1418-1427. doi:10.1177/0146167213499186

Leask, B. (2009). Using formal and informal curricula to improve interactions between home and international students. Journal of Studies in International Education, 13(2), 205-221. doi:10.1177\%2F1028315308329786

Lee, J. Y., \& Ciftci, A. (2014). Asian international students' socio-cultural adaptation: Influence of multicultural personality, assertiveness, academic self-efficacy, and social support. International Journal of Intercultural Relations, 38, 97-105. doi:10.1016/j.ijintrel.2013.08.009

Liu, D. (2016). Strategies to promote Chinese international students' school performance: Resolving the challenges in American higher education. Asian-Pacific Journal of Second and Foreign Language Education, 1(1), 1-15. doi:10.1186/s40862-016-0012-9

Liu, T. (2016). Learning experience of Chinese international students in master of education program at a mid-sized Ontario university (Master's thesis). University of Windsor, ON. Retrieved from http://scholar.uwindsor.ca/etd/5841/

Maestas, R., Vaquera, G. S., \& Zehr, L. M. (2007). Factors impacting sense of belonging at a Hispanic-serving institution. Journal of Hispanic Higher Education, 6, 237-256. doi: $10.1177 / 1538192707302801$

Malinga-Musamba, T. (2014). First-year course experience and college adjustment: A case study. Journal of Psychology in Africa, 24(3), 278-280. doi:10.1080/14330237.2014.903067

Mamiseishvili, K. (2012). Academic and social integration and persistence of international students at U.S. two-year institutions. Community College Journal of Research and Practice, 36(1), 15-27. doi:10.1080/10668926.2012.619093

Masika, R., \& Jones, J. (2016). Building student belonging and engagement: Insights into higher education students' experiences of participating and learning together. Teaching in Higher Education, 21(2), 138-150. doi:10.1080/13562517.2015.1122585

Maslow, A. H. (1954). Motivation and personality. New York, NY: Harper \& Row. 
Oseguera, L., \& Rhee, B. S. (2009). The influence of institutional retention climates on student persistence to degree completion: A multilevel approach. Research in Higher Education, 50(6), 546-569. doi:10.1007/s11162-009-9134-y

O'Keeffe, P. (2013). A sense of belonging: Improving student retention. College Student Journal, 47(4), 605-613.

Paltridge, T., Mayson, S., \& Schapper, J. (2012). Covering the gap: Social inclusion, international students and the role of local government. Australian Universities' Review, 54(2), 29-39. Retrieved from https://eric.ed.gov/?id=EJ981191

Pittman, L. D., \& Richmond, A. (2007). Academic and psychological functioning in late adolescence: The importance of school belonging. Journal of Experimental Education, 75, 270-290. doi:10.3200/JEXE.75.4.270-292

Ryan, R. M., \& Deci, E. L. (2002). An overview of self-determination theory: An organismicdialectical perspective. In E. L. Deci \& M. R. Ryan (Eds.), Handbook of self-determination research (pp. 3-33). Rochester, NY: University of Rochester Press.

Slaten, C. D., Elison, Z. M., Lee, J. Y., Yough, M., \& Scalise, D. (2016). Belonging on campus: A qualitative inquiry of Asian international students. Counseling Psychologist, 44(3), 383410. doi:10.1177/0011000016633506

Slaten, C. D., Yough, M. S., Shemwell, D., Scalise, D. A., Elison, Z. M., \& Hughes, H. (2014). "Eat. Sleep. Breathe. Study": Understanding what it means to belong at a university from the student perspective. Excellence in Higher Education, 5, 1-5. doi:10.5195/ehe.2014.117

Strayhorn, T. L. (2012). College students' sense of belonging: A key to educational success for all students. New York, NY: Routledge.

Tinto, V. (1975). Dropout from higher education: A theoretical synthesis of recent research. Review of Educational Research, 45(1), 89-125. doi:10.3102/00346543045001089

Vaccaro, A., Daly-Cano, M., \& Newman, B. M. (2015). A sense of belonging among college students with disabilities: An emergent theoretical model. Journal of College Student Development, 56(7), 670-686. doi:10.1353/csd.2015.0072

Van Orden, K. A., Witte, T. K., James, L. M., Castro, Y., Gordon, K. H., Braithwaite, S. R., Hollar, D. L., \& Joiner, T. E. (2008). Suicidal ideation in college students varies across semesters: The mediating role of belongingness. Suicide and Life-Threatening Behavior, 38(4), 427-435. doi:10.1521/suli.2008.38.4.427

Wang, C. D., \& Mallinckrodt, B. (2006). Acculturation, attachment, and psychosocial adjustment of Chinese/Taiwanese international students. Journal of Counseling Psychology, 53(4), 422-433. doi:10.1037/0022-0167.53.4.422

Wang, P. Y. (2016). A study of drop-out Chinese international students from a Canadian preuniversity English language improvement program: Acculturation experiences and challenges (Master's thesis). University of Windsor, ON. Retrieved from http://scholar.uwindsor.ca/etd/5873/

Yan, Z., \& Sendall, P. (2016). First year experience: How we can better assist first-year international students in higher education. Journal of International Students, 6(1), 35-51. Retrieved from http://files.eric.ed.gov/fulltext/EJ1083270.pdf

Yao, C. W. (2016). "Better English is the better mind": Influence of language skills on sense of belonging in Chinese international students. Journal of College and University Student Housing, 43(1), 74-88. 
Yu, Z. R. (2018). A study of Chinese international students' classroom participation in an international M.Ed. program (Master's thesis). University of Windsor, ON. Retrieved from https://scholar.uwindsor.ca/etd/7419/

Zhang, Z., \& Xu, J. (2007). Understanding Chinese international graduate students' adaptation to learning in North America: A cultural perspective. Higher Education Perspectives, 3(1), 4559. Retrieved from https://ir.lib.uwo.ca/cgi/viewcontent.cgi?article=1059\&context=cie-eci

Zhou, G., Liu, T., \& Rideout, G. (2017). A study of Chinese international students enrolled in the Master of Education program at a Canadian university: Experiences, challenges, and expectations. International Journal of Chinese Education, 6(2), 210-235. doi:10.1163/22125868-12340081

Zhou, G., \& Zhang, Z. (2010). Understanding Chinese international students at a Canadian university: Perspectives, expectations, and experiences. Canadian and International Education, 39(3), 43-58. Retrieved from http://ir.lib.uwo.ca/cie-eci/vol39/iss3/5/

Zhou, G., \& Zhang, Z. (2014). A study of the first year international students at a Canadian university: Challenges and experiences with social integration. Canadian and International Education, 43(2), 1-17. Retrieved from http://ir.lib.uwo.ca/cie-eci/vol43/iss2/7 